\title{
Erratum to: A new method for automatically constructing domain-oriented term taxonomy based on weighted word co-occurrence analysis
}

\author{
Shuqing $\mathrm{Li}^{1} \cdot$ Ying Sun $^{2} \cdot$ Dagobert Soergel $^{2}$
}

Published online: 12 January 2016

(C) Akadémiai Kiadó, Budapest, Hungary 2016

\section{Erratum to: Scientometrics (2015) 103:1023-1042 \\ DOI 10.1007/s11192-015-1571-0}

In the original publication of this article, affiliation of Dr. Shuqing Li has been mentioned incorrectly. The correct affiliation is provided in this erratum.

The online version of the original article can be found under doi:10.1007/s11192-015-1571-0.

Shuqing Li

leeshuqing@gmail.com

1 Department of Information Management and Information System, College of Information Engineering, Nanjing University of Finance and Economics, Nanjing 210046, China

2 Department of Library and Information Studies, Graduate School of Education, University at Buffalo, The State University of New York, Buffalo, NY 14260-1660, USA 